\author{
Ärztliche Erfahrung beschränkt sich nicht auf medizinisches Fachwissen. Sie \\ entsteht auch aus den mehr oder minder alltäglichen, heiter, ärgerlich oder \\ nachdenklich stimmenden Erlebnissen mit Patienten, Kollegen und Mitarbeitern. \\ Senden Sie uns Ihre Geschichte an: Brigitte.Moreano@springer.com. Für jeden \\ veröffentlichten Text erhalten Sie bis zu 100 Euro.
}

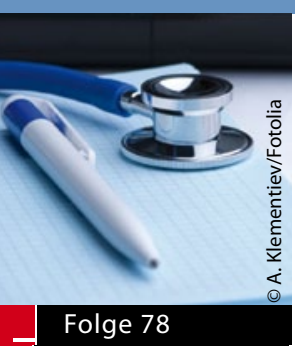

\title{
Geschichten aus dem Rettungsdienst
}

— Kürzlich sprach ich mit einem jungen Rettungssanitäter, der mir von seinem letzten Dienst an einem Samstag berichtete: "Fast alles sinnlose Einsätze", sagte er, "hauptsächlich Betrunkene".

Laut Gesetz muss die Besatzung eines Rettungswagens Patienten auch dann mitnehmen, wenn hierfür kein offensichtlicher Anlass besteht. Und so musste das Team eben allerlei Betrunkene einpacken, die sie lallend mit voll urinierten Hosen und Erbrochenem vor dem Mund erwarteten. Die anderen Anwesenden konstatierten nur, dass sie nicht wüssten, was sie mit den Zechkumpanen anfangen sollten.

Ein anderer Besuch führte das Rettungsteam zu einem älteren Herrn mit künst-

\section{Oh Schreck, die Zeck' ist weg!}

- Was die Reaktion auf Zeckenbisse angeht, kann mich nichts mehr überraschen -dachte ich. Vom stoischen alten Herrn, bei dem ich zufällig eine große Zecke in der Leiste entdecke, die der noch gar nicht bemerkt hat: ${ }^{\prime}, . .$. aber so kriegt man sie ja auch besser zu packen ..., bis zur panischen Schülerin, die als "Notfall" mitten aus der Schulstunde kommt, weil sie da eine bei sich in der Ellenbeuge gefunden hat und diese keine Sekunde länger erträgt. Ich habe sogar erhebliche Hautdefekte gesehen, weil jemand mit der Nagelschere versucht hat, ja alle verbliebenen Zeckenreste zu entfernen.

Neulich war wieder ein Fall als „eilig“ angemeldet: eine Mutter, die morgens beim licher Hüfte. Er klagte über Schmerzen, und darum hatte die Tochter den Rettungswagen bestellt. Sie sei keineswegs in der Lage, die Verantwortung für den Transport ihres Vaters im eigenen Auto zu übernehmen, hatte sie bemerkt. In der Wohnung fand sich dann ein agiler älterer Herr, der das Angebot des Transportes im Tragestuhl entrüstet ablehnte und recht hurtig die Treppen zum Krankenwagen hinunter ging.

Immer noch wird aus schlichter Bequemlichkeit die 112 gewählt, selbst wenn gar kein Notfall vorliegt, Nur, weil man keine Lust hat, bei ungemütlichem Wetter oder nächtlicher Stunde das eigene Auto zu verwenden, oder weil man das Eintreffen des hausärztlichen Bereitschafts-

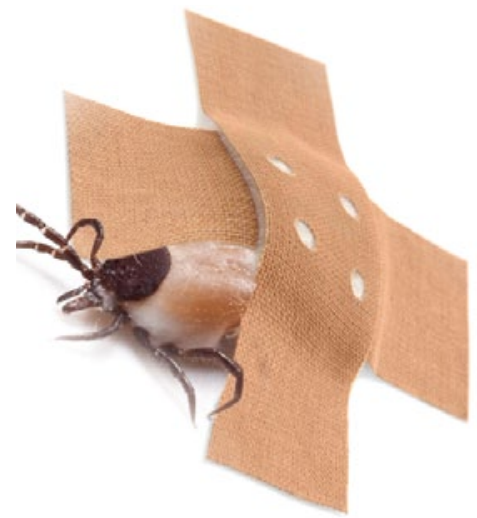

Anziehen bei ihrem knapp zweijährigen Sohn eine Zecke in seiner Bauchhaut entdeckt hatte. Natürlich durfte sie noch in die ohnehin schon überfüllte Sprechstunde kommen, um das Untier entfernen zu lassen. Der Junge erschien an der Hand der besorgten Mutter und hob bereitwillig sein TShirt hoch, um sich untersuchen zu lassen. Allerdings konnte ich keine Zecke entdecken. dienstes nicht abwarten mag. Der Versuch, den Missbrauch durch Zusendung einer Rechnung zu ahnden, geht meistens schief, und die Krankenkassen bezahlen am Ende die Zeche doch (um sich das Geld über die Gebührensätze von der Allgemeinheit wieder hereinzuholen).

So lange unser Rettungsdienst ein Selbstbedienungsladen ist und selbst die Zecher ein gemütliches Krankenhausbett und körperliche Reinigung für $500 €$ die Nacht in Anspruch nehmen dürfen, ist von ernsthaften Sparbemühungen keine Rede! Kein Wunder, wenn das Rettungspersonal bis auf die Knochen frustriert ist.

Dr. med. Frauke Höllering, ARnSberg =

Ehe ich meiner Verwunderung darüber Ausdruck geben konnte, zeigte die Mutter auf eine punktförmige Rötung neben dem Bauchnabel. Sie berichtete, ihr Sohn habe die Zecke gepackt und herausgezogen, ehe sie ihn davon abhalten konnte. Sie habe schon mit ihm geschimpft, es aber nicht mehr rückgängig machen können.

Beeindruckt von den offenkundig schon gut entwickelten feinmotorischen Fähigkeiten des Kindes desinfizierte ich die Bissstelle und klebte dem Kleinen ein Pflaster mit Jodsalbe darauf, schon zur Kennzeichnung des Bereiches und natürlich zur Beruhigung der Mutter.

DR. MED.ANDREA LINSEL, LÜNEBURG = 